\title{
Rescue lumen-apposing metal stent to treat a perforation secondary to balloon dilation of a Crohn's disease stenosis
}

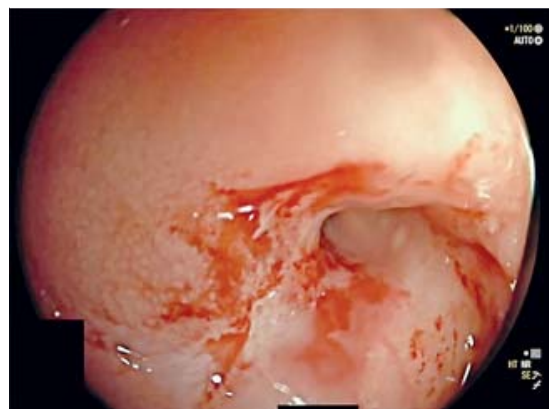

- Fig. 1 Colonic stenosis located $30 \mathrm{~cm}$ from the anal margin.

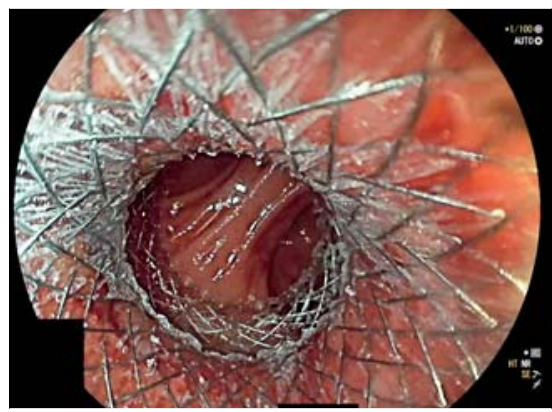

Fig. 4 Positioning of a 15-mm lumenapposing metal stent.

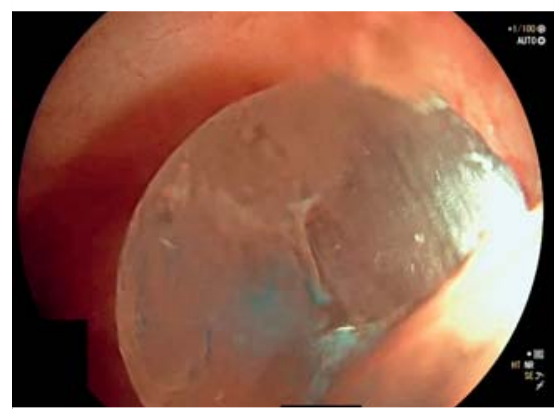

Fig. 2 Hydrostatic dilatation was performed up to $15 \mathrm{~mm}$.

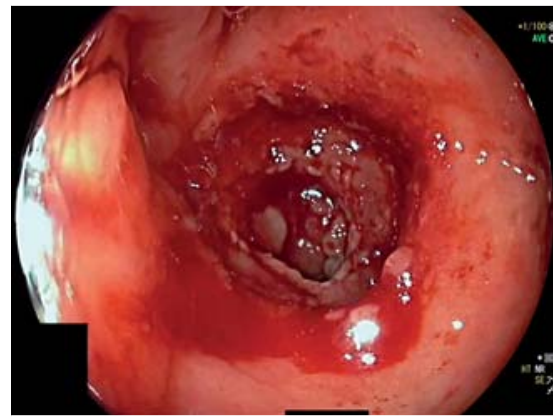

- Fig. 5 Good healing was confirmed 1 month later.

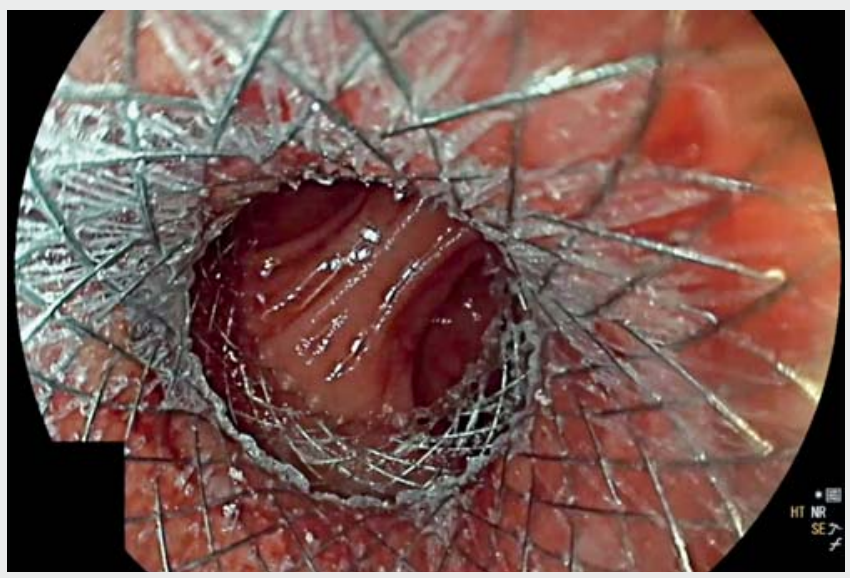

$\checkmark$ Video 1 Rescue lumen-apposing metal stent to treat a perforation secondary to balloon dilation of a Crohn's disease stenosis.

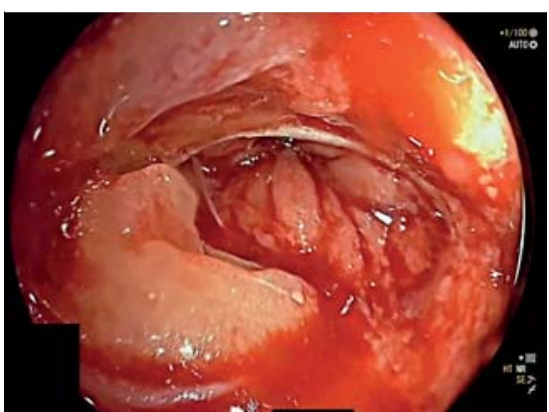

Fig. 3 Visualization of pericolic fat confirmed perforation.

A 61-year-old woman was followed for ileocolic Crohn's disease (CD) with multicomplicated colonic and ano-perineal involvement, evolving over 17 years, with a subtotal colectomy protected by an upstream lateral ileostomy. Optimized adalimumab allowed control of the disease with healing of fistulas.

However, a scarring colonic stenosis ( $\triangleright$ Fig. 1) persisted $30 \mathrm{~cm}$ from the anal margin; it could not be crossed by an endoscope and prevented restoration of continuity. Hydrostatic endoscopic dilatation ( $\triangleright$ Fig. 2, $\triangleright$ Video 1 ) up to $15 \mathrm{~mm}$ was performed after multidisciplinary discussion. After dilation, visualization of pericolic fat confirmed digestive perforation ( $\triangleright$ Fig. 3 ). The proximity between the perforation and the ileocolic anastomosis did not allow the option of a covered metallic stent. A 15-mm lumen apposing metal stent (LAMS) was used ( $\mathbf{F i g . 4 )}$ ). The colonoscope was removed and a therapeutic gastroscope was substituted because of the excessive length of the working channel of the colonoscope $(140 \mathrm{~cm})$. Release of the two flanges was performed under endoscopic guidance, and good positioning was confirmed by opacification without any leakage.

The post-procedure care was easy, with only 5 days of oral antibiotics and return home on the first day. The LAMS was re- 
moved 1 month later with perfect healing of both the perforation and the stenosis ( $\triangleright$ Fig.5). The patient presents stool by the anus for the first time in 4 years, and removal of the ileostomy is being discussed. In cases of perforation during dilation of short fibrous stenosis, off-label use of LAMS through a therapeutic gastroscope seems to be a promising rescue solution.

Endoscopy_UCTN_Code_CPL_1AJ_2AF

Competing interests

The authors declare that they have no conflict of interest.
The authors

Raphael Olivier ${ }^{1}$, Stéphane Scheer ${ }^{1}$, Jérémie Albouys $^{2}$, Marion Schaefer ${ }^{3}$, Abdelkader Taibi $^{2}$, Sophie Geyl ${ }^{2}$, Jérémie Jacques ${ }^{2}$

1 Poitiers University Hospital Center, HepatoGastroenterology Department, Poitiers, France

2 Limoges University Hospital Center, HepatoGastroenterology Department, Limoges, France

3 Nancy University Hospital Center, HepatoGastroenterology Department, Nancy, France

\section{Corresponding author}

\section{Raphael Olivier, MD}

Hepato-Gastroenterology Department, Poitiers University Hospital Center, 2 Rue de la Milétrie, 86000 Poitiers, France

Fax: +33-5-49-44-38-35

raphael.olivier@chu-poitiers.fr
Bibliography

Endoscopy 2022; 54: E197-E198

DOI 10.1055/a-1463-2333

ISSN 0013-726X

published online 12.5.2021

(c) 2021. Thieme. All rights reserved.

Georg Thieme Verlag KG, Rüdigerstraße 14, 70469 Stuttgart, Germany

\section{ENDOSCOPY E-VIDEOS}

https://eref.thieme.de/e-videos

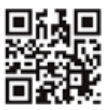

Endoscopy E-Videos is an open access online section, reporting on interesting cases and new techniques in gastroenterological endoscopy. All papers include a high quality video and all contributions are freely accessible online. Processing charges apply (currently EUR 375), discounts and wavers acc. to HINARI are available.

This section has its own submission website at

https://mc.manuscriptcentral.com/e-videos 